\title{
Expressions of TOLL-like receptor 4 (TLR-4) and matrix metalloproteinase 9 (MMP-9)/Tissue inhibitor of metalloproteinase 1 (TIMP-1) in pulmonary blood vessels with chronic obstructive pulmonary diseases and their relationships with pulmonary vascular remodelling
}

Wen-Cheng $\mathrm{Yu}^{* 1}$ Jin-Peng Cong ${ }^{1}$

Li-Yun Mi ${ }^{1}$

1. Department of Respiratory Medicine, the Affiliated Hospital of Qingdao University, Qingdao 266003 , China

\section{SUMMARY}

OBJECTIVE: This study aims at investigating the expressions of TOLL-like receptor 4 (TLR-4) and matrix metalloproteinase 9 (MMP-9)/ tissue inhibitor of metalloproteinase 1 (TIMP-1) in pulmonary blood vessels with chronic obstructive pulmonary disease (COPD) and their relationships with pulmonary vascular remodelling (PVR).

METHODS: 60 para-tumour tissues were divided into the COPD group and the control group ( $n=30)$; the inflammations, pulmonary artery wall area/total artery area (WA\%), and wall thickness/vascular outer diameter (WT\%) were compared. The expressions of TLR-4, MMP9/TIMP-1, and PCNA in pulmonary vascular smooth muscle cells were detected, and their relationships with PVR were then analysed.

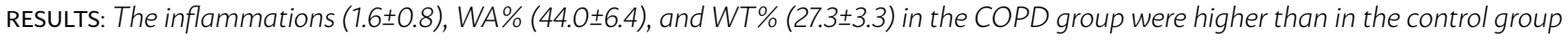
$(0.3 \pm 0.5,26.1 \pm 2.8,15.6 \pm 1.8)$, and the expressions of TLR-4 (31.4 \pm 14.7$)$ and MMP-9/TIMP-1 (2.2 \pm 2.6$)$ were increased compared to the control group (4.7 $\pm 4.5,1.9 \pm 1.2)$. Correlation analysis: $T L R-4$ and MMP-9/TIMP-1 were positively correlated with the inflammations $(r=0.18, P<0.01)$, WA\% ( $r=0.68, P<0.01)$, and WT\% $(r=0.73, P<0.01)$, as well as positively correlated with the expression of PCNA ( $r=0.44$, $P<0.01)$; the upregulation of TLR-4 was positively correlated with the expressions of MMP-9 and TIMP-1.

CONCLUSIONS: The upregulation of TLR-4 in the pulmonary arterial smooth muscle cells of COPD patients could promote the inflammations and the MMP-9 expression, thus causing abnormal degradation of extracellular matrix, so it played an important role in the process of $P V R$.

KEYWORDS: Lung diseases. Pulmonary disease, chronic obstructive. Matrix Metalloproteinase 9. Myeloid differentiation factor 88. Tissue inhibitor of metalloproteinases. Remodelling.

\section{INTRODUCTION}

Chronic obstructive pulmonary disease (COPD) has become an increasingly serious global health issue, and the World Health Organization (WHO) estimates that COPD will rank the fifth of the worldwide disease burdens by 2020; multi-regional epidemiological surveys in China showed that the prevalence rate of COPD in people over 40 years old was $8.2 \%$, and the prevalence increased significantly in older people. ${ }^{1}$ As a progressive disease, its main characteristics are inflammations and lung function deterioration, and the pathological fea- 
tures are mainly emphysema, mucus hypersecretion, chronic inflammations in airway and vessels, and remodelling. TOLL-like receptors (TLR) are an important class of pattern recognition receptors, as the main receptors mediating the lipopolysaccharide or endotoxin signal transductions, which originate from the outer membrane of the cell wall of Gram-negative bacteria, TLR could activate signal transduction pathways, induce the expressions of a variety of immune responsive genes, and is involved in the occurrence and development of COPD and other inflammatory diseases. ${ }^{2-5}$ It has been proven that the high expression of TLR- 4 could cause lung cells to produce a variety of inflammatory cytokines, interfere the Th1/Th2 balance, thus inducing such common respiratory diseases characterized by bronchial spasm, obstruction, inflammatory cell infiltration and destruction; furthermore, it could regulate the expressions of matrix metalloproteinase 9 (MMP-9)/tissue inhibitor of metalloproteinase 1 (TIMP-1) in multiple ways. ${ }^{6-12}$ MMP-9 is an important enzyme regulating the synthesis and degradation of extracellular matrix, and TIMP-1 is the specific inhibitor of MMP-9, synthesized and secreted by macrophages, endothelial cells, fibroblasts, tumour cells, etc., and could inhibit the activities of MMP-9 mainly by blocking the self-activation of pro-matrix metalloproteinases, and specifically binding with $\mathrm{Zn}^{2+}$, located in the catalytic activity centre of MMP-9 and forming stable complex. The ratio imbalance between these two was closely related with the persistent activation of chronic airway inflammations, tissue damages, repairing and remodelling, and revascularization. ${ }^{13-15}$ Currently, studies are mostly focused on airway inflammation, oxidative stress, and airway remodelling, etc., and less on pulmonary vascular remodelling (PVR); furthermore, these studies used more animals or in vitro cultured pulmonary arterial smooth muscle cells, which are different from human specimens, so the results would be different. This study used human specimens as subject, aiming at reflecting the actual expression situations of COPD-related factors. By detecting the expressions of TLR-4 and MMP-9/TIMP-1 in pulmonary vascular smooth muscle cells, combined with detecting the related indexes, this study explored the roles of their expressions in the PVR process, thus providing new theoretical basis for further clarifying the mechanisms of PVR in COPD.

\section{MATERIALS AND METHODS}

\section{Study population}

The lung tissues were sampled from male patients with well-differentiated squamous cell carcinoma in the department of thoracic surgery of our hospital from January 2012 to May 2013. After measuring the lung functions before surgery, all patients were divided into the COPD group and the control group (30 cases each) according to the diagnosis and treatment standards of COPD. ${ }^{16}$ Patients with lung malfunctions caused by airway-obstructing tumour were excluded, and the enrolled COPD patients had no other lung disease or chronic disease in other systems. The patients in the COPD group were in a stable stage, and the age difference between the two groups was not significant; no other systemic disease existed. This study was conducted in accordance with the declaration of Helsinki. This study was conducted with approval from the Ethics Committee of the Qingdao University. Written informed consent was obtained from all participants.

The normal periphery tissues that were over 5 $\mathrm{cm}$ away from the lung tumour and not infiltrated were selected, followed by formalin fixation, ethanol dehydration, xylene hyalinization, paraffin embedding, and preparation of $3 \mu \mathrm{m}$ paraffin slices. The tissue specimens' properties were confirmed by pathologists.

\section{Hematoxylin-Eosin (HE) staining}

The pulmonary morphological and structural changes were observed under an optical microscope, and 100-500 $\mu \mathrm{m}$ in diameter arteries were selected for semi-quantitatively evaluation of the levels of arterial wall and surrounding inflammatory cell infiltration. Scoring criteria: no inflammatory cell infiltration: 0 point; minor inflammatory cell infiltration: 1 point; more inflammatory cell infiltration with uneven distribution: 2 points; more inflammatory cell infiltration and even distribution, but not gathered into clumps: 3 points; many inflammatory cell infiltration gathered into clumps: 4 points; five small pulmonary arteries with relatively round cross-section were then randomly selected for Dotslide imaging and measurement of inner and outer diameters of pulmonary arterioles, wall thickness, and wall area, and then WT\% and WA\% were calculated. 


\section{Immunohistochemically staining}

The PV two-step method of immunohistochemically staining was used, and the operations were performed strictly according to the kit instructions. Rabbit anti-human MMP-9 polyclonal-antibody, rabbit anti-human TIMP-1 polyclonal-antibody and mouseanti-human PCNA were obtained from ZSGBBIO (Beijing, China), rabbit anti-TLR4 antibody was obtained from BIOSS (Beijing, China). All other chemicals used were of the best commercially available grade. Each slice was randomly collected, five pulmonary arteries with 100 500 $\mu \mathrm{m}$ in diameter $(\times 400)$ : the positive expression of MMP-9 and TIMP-1 was characterized as brown cytoplasm, and that of TLR4 was buffy cytoplasm and/or cell membrane; the percentage of the cells with positive MMP-9, TIMP-1 and TLR- 4 to the overall pulmonary vascular smooth muscle cells were then observed and counted. Proliferating Cell Nuclear Antigen (PCNA) was synthesized in nuclei, and the cells appearing brown granules were proliferating; the percentage of the cells with positive PCNA to the overall pulmonary vascular smooth muscle cells were then counted. The overexpression of PCNA indicated active cell proliferation and apoptosis reduction.

\section{Statistical analysis}

The data was analysed using SPSS17.0 statistical software. The measurement data was expressed as mean \pm standard deviation $(\bar{x} \pm \mathrm{s})$. The intergroup comparison method used the $t$ test, and the related

\section{FIGURE 1}

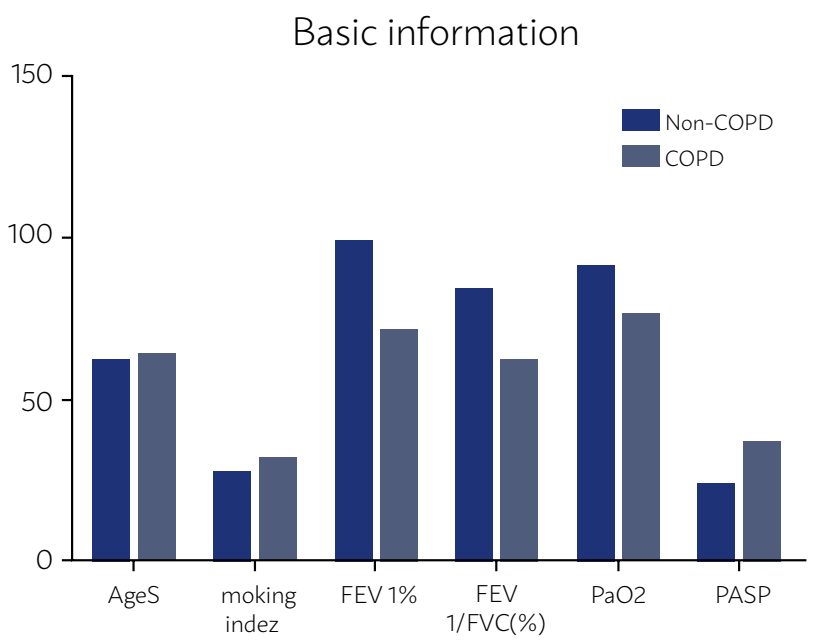

Figure 1. Comparison of basic situation and lung functions between the two groups $(\bar{x} \pm s)$. indicators were compared using the Pearson correlation analysis, with $P<0.05$ considered statistically significant.

\section{RESULTS}

\section{Characteristics of the study groups}

All the patients were male, and there was no statistically significant age difference $(P>0.05)$. The lung function, percentage of the first second forced expiratory volume to the estimated value (FEV1\%), percentage of the first second forced expiratory volume to the forced vital capacity (FEV1/FVC\%) in the COPD group were significantly lower than in the control group $(P<0.01)$ (Figure 1).

\section{Comparison of HE staining results}

Under light microscope, the pulmonary vascular wall in the control group was complete and not thickened, without or with rare inflammatory cells around; the bronchial mucosa was intact, and the alveolar structures were normal. The lung vascular wall and surrounding tissues in the COPD group exhibited the infiltration of a large number of monocytes and lymphocytes, and the pulmonary vascular wall was significantly thickened. Compared with the control group, the patients in the COPD group exhibited significant inflammatory cell infiltration in pulmonary artery lumen and surrounding tissues, and the inflammation score was significantly higher $(P<0.01)$; meanwhile, the arterial wall was thickened, the lumen was narrowed, and smooth muscle proliferation and collagen deposition appeared significantly; WT\% and WA\% in the COPD group were significantly higher than in the control group $(P<0.01)$ (Table 1$)$.

TABLE 1. RESULTS OF LUNG TISSUE IMAGE ANALYSIS IN THE TWO GROUPS $(X \pm S)$

\begin{tabular}{l|l|l|l|l}
\hline Group & Cases & Inflammation score & WT\% & WA\% \\
\hline Control & 30 & $0.3 \pm 0.5$ & $15.6 \pm 1.8$ & $26.1 \pm 2.8$ \\
\hline COPD & 30 & $1.6 \pm 0.8$ & $27.3 \pm 3.3$ & $44.0 \pm 6.4$ \\
\hline$T$ & & -7.824 & -17.140 & -13.949 \\
\hline$P$ & & $<0.01$ & $<0.01$ & $<0.01$ \\
\hline
\end{tabular}




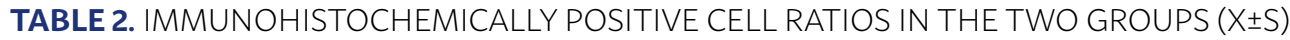

\begin{tabular}{c|c|c|c|c|c|c}
\hline Group & Cases & TLR4 (\%) & MMP-9 (\%) & TIMP-1 (\%) & MMP-9/TIMP-1 (\%) & PCNA (\%) \\
\hline Control & 30 & $4.7 \pm 4.5$ & $5.5 \pm 6.1$ & $4.1 \pm 4.2$ & $1.9 \pm 1.2$ & $9.4 \pm 4.8$ \\
COPD & 30 & $31.4 \pm 14.7$ & $39.2 \pm 24.0$ & $32.8 \pm 22.4$ & $2.2 \pm 2.6$ & -0.65 \\
T & & -9.6 & -7.5 & -6.9 & $<0.01$ & -5.9 \\
P & & $<0.01$ & $<0.01$ & $<0.01$ & $<0.01$ \\
\hline
\end{tabular}

\section{Comparison of immunohistochemically results}

The immunohistochemically results showed that the expression levels of TLR4, MMP-9, TIMP-1, and PCNA in the pulmonary vascular smooth muscle cells of the COPD group were significantly higher $(P<0.01)$ (Table 2).

\section{Correlation analysis}

The expression of TLR-4 in pulmonary vascular smooth muscle cells was positively related with the PVR-associated indicators (WT\%, WA\%) $(\mathrm{r}=0.73,0.68, P<0.01)$, PCNA ( $\mathrm{r}=0.44, P<0.01)$, inflammations ( $\mathrm{r}=0.48, P<0.01)$, and MMP-9/TIMP-1 ratio $(\mathrm{r}=0.18, P<0.01)($ Table 3$)$.

\section{DISCUSSION}

Chronic pulmonary vascular inflammations caused inflammation injuries, and repair-caused extracellular matrix increasing, proliferation of smooth muscle cells, hypertrophy of pulmonary artery muscles, stenosis, and blood vessel elasticity decreasing would cause PVR and pulmonary hypertension, as well as eventually result in the occurrence of ventricular remodelling and pulmonary heart disease. Chronic inflammations play an important role in PVR. Researches had shown that mild COPD patients without hypoxia and long-term smokers not meeting the diagnostic criteria already had significant pulmonary vascular inflammations, and abnormal pulmonary vascular structures and PVR could also be seen. ${ }^{17}$ This study found many inflammatory cells

TABLE 3. CORRELATION BETWEEN TLR4(\%) AND WT\%,WA\% PCNA(\%), MMP-9/TIMP-1, INFLAMMATION SCORE.

\begin{tabular}{l|l}
$R(P<0.01)$ & TLR4 $(\%)$ \\
\hline WT \% & 0.73 \\
\hline WA \% & 0.68 \\
\hline PCNA (\%) & 0.44 \\
\hline MMP-9/TIMP-1 & 0.18 \\
\hline Inflammation score & 0.48 \\
\hline
\end{tabular}

existing around the pulmonary vessels in the COPD group, and the inflammation score was significantly higher than in the control group, consistent with other researches. ${ }^{17}$ Sustained inflammation activation would release a variety of inflammatory mediators, thus promoting the activation of a variety of inflammatory cells; the interactions among cells could produce a variety of cytokines, which would then act on the pulmonary vascular smooth muscle cells and endothelial cells, promoting the proliferation of stromal cells, repetitively carrying out injury-repair processes, and involved in PVR. It was confirmed that the increased inflammatory cells in lung tissues were positively correlated with the destruction degree of lung parenchyma, as well as closely related to the degree of airflow restriction. With the aggravation of the disease and the declining of the lung functions, the number of inflammatory cells in lung tissues were increased. ${ }^{18}$ This study showed that the pulmonary vascular wall and surrounding tissues of COPD patients exhibited a large number of inflammatory cell infiltration, the pulmonary vascular wall was significantly thickened, the smooth muscle cells exhibited significant hypertrophy, the intercellular substances were increased, and the lumen was narrowed, namely exhibiting significant PVR. Image analysis showed that, compared with the non-COPD group, the inflammation score, WT\%, and WA\% in the COPD group were significantly higher $(P<0.01)$, and the inflammation score was positively correlated with WT\% and WA\% $(P<0.01)$. The inflammations in pulmonary vessels might occur in early COPD stage, and the inflammatory cells might migrate from the bronchial arteries, thus directly or indirectly contributing to PVR.

Vascular inflammations were also closely related with the expression of TLR-4. Toll-like receptors (TLRs) belong to the recognition receptors of pathogen-associated molecular patterns (PAMPs), and could recognize PAMPs, thus activating the intracellular signalling pathways, promoting the release of inflammatory factors, and closely relating to the human innate 
immunity and acquired immunity. Presently, TLR4 has been much studied; TLR4 is the main receptor of Gram-negative bacterial lipopolysaccharide, and its high-expression is associated with a variety of diseases; it could promote inflammations thus exacerbating disease severities. The TLR4 signal transduction pathways could be divided into the myeloid differentiation factor 88 (MyD88)-dependent and non-dependent pathways, in which the former is mainly through activating NF-KB, and then starting gene transcriptions and promoting the expressions of inflammatory factors; the latter is through binding the TLR-4 intracellular Toll-IL-1 receptor domain with the respective molecules, thus inducing the interferon regulatory factors to enter the nuclei, followed by promoting the maturation of dendritic cells and the expression of interferon. ${ }^{19,20}$ The overexpression of TLR-4 gene in pulmonary cells might be caused by producing interferon and various inflammatory cytokines, thus participating in the chronic inflammations of COPD, inducing the influx of inflammatory cells, changing the lung vascular permeability, promoting the increasing of matrix metalloproteinase and other active substances, and further exacerbating the injury-repair process. The inflammatory cytokines produced by a variety of inflammatory cells, as well as the pathological changes of vascular endothelial cells, smooth muscle cells, fibroblasts, etc., are the leading cause for PVR. The accumulation of inflammatory cells and the production of inflammatory cytokines are closely related to the expression of TLR4. This study showed that the expression of TLR- 4 in the COPD group was significantly increased, and the inflammatory cell infiltration was more significant; its expression level was positively correlated with WA\% and WT\%, and closely related to the expression of PCNA, suggesting that TLR-4 participated in the COPD inflammation, and was closely related to the proliferation of lung vascular smooth muscles. Some scholars found that simvastatin could inhibit the protein expressions of NF- $\kappa$ B, MUC5AC, and TLR- 4 in the airway and lung tissues, thereby reducing the roles of airway inflammations and airway mucus hypersecretion. ${ }^{21}$

The upregulation of TLR- 4 and its ligands could affect the metabolic balance of extracellular matrix, and participate in PVR. TLR-4 could induce the apoptosis of matrix-producing cells by the Fas-associated death domain pathways, resulting in the reduction of extracellular matrix; on the other hand, TLR- 4 could induce macrophages to secrete MMP-9 so as to break down extracellular matrix. ${ }^{22}$ MMP-9 is one member of the matrix metalloproteinases family, with its substrates mainly as gelatine, elastic fibres, and type IV, V, VII, and X collagens. MMP-9 could regulate cell adhesion, act on extracellular components or other protein components, thus involved in pathophysiological processes as angiogenesis, tissue remodelling, embryogenesis, or wound healing. ${ }^{23}$ The results of this study showed that the expression of MMP-9 in the COPD group was significantly increased, and positively correlated with the expression of TLR-4; TLR-4 regulated the expression of MMP-9 via the NF-KB activation pathway. ${ }^{6}$ The increased expression of MMP9 in vascular smooth muscle cells would disturb the metabolism of extracellular matrix in vascular walls, promote the proliferation and migration of vascular smooth muscles, thus resulting in the vascular wall thickening and lumen stenosis. TIMP-1 is the specific inhibitor of MMP-9, and could be synthesized and secreted by a variety of inflammatory cells and lung structural cells; it might inhibit the MMP-mediated endothelial cell migration, and inhibit the angiogenesis. Since it has cell growth factor-like effects, it could promote the collagen synthesis and fibroblast proliferation, inhibit the extracellular matrix (ECM) degradation, and promote its deposition. The increased ratio of MMP-9/TIMP-1 was found to be related with a variety of lung diseases. ${ }^{24}$ Some scholars found the imbalanced MMP-9/TIMP-1 ratio in the sputum of COPD patients, which was significantly increased in acute exacerbation, suggesting that it was related to the lung tissue remodelling. ${ }^{25,26}$ The results of this study showed a significant increase of the MMP-9/TIMP-1 ratio in the COPD group, as well as the high expressions of MMP-9 and TIMP-1 in the wall smooth muscle cells, indicating that in the vascular wall of COPD patients there was the imbalance of proteases - anti-proteases; due to the imbalance of these two, the pulmonary vessels were damaged, and the repairing balance was also destroyed. Therefore, the occurrence and development of PVR were accelerated. Some scholars also found that in the rat model with monocrotaline-induced right ventricular hypertrophy, the degrees of pulmonary arterial muscularization and collagen deposition were related with the high expressions of MMP-9 and TIMP-1proteins, ${ }^{27}$ consistent with the results of this study.

The etiology and pathogenesis of PVR in COPD are involved in many factors, and the specific mechanisms are not fully understood, yet. This study 
showed that inflammations might be the initiating factor of PVR appearing in early COPD, and the upregulation of TLR-4 might exacerbate the inflammations, as well as promote the expression of MMP-9 to be increased. Therefore, the MMP-9/TIMP-1 ratio was significantly increased, followed by the metabolic disorders of ECM in vascular walls and the induced proliferation of pulmonary vascular smooth muscles, which all played important roles in the process of PVR. This study used human specimens, unlike animal-only studies. Patients with severe COPD could not tolerate surgeries due to their fragile hearts and lung functions, so their lung tissues are difficult to obtain. Therefore, this study still lacked the corresponding expression data of the above pulmonary vascular smooth muscle cell-associated factors. Meanwhile, this study was only in mild-moderate COPD patients, so it had some limitations; however, through further studying the mechanisms of PVR in COPD, this study provided more evidence for the treatment of PVR. When inhibiting inflammatory responses, physical or chemical methods could be performed to intervene the expression of TLR-4, and this might become an effective way towards the prevention and treatment of PVR, pulmonary hypertension, and pulmonary heart disease.

\section{CONFLICT OF INTEREST}

The authors declare that they have no conflict of interest.

\section{RESUMO}

OBJETIVO: Este estudo tem como objetivo investigar as expressões de TOLL-like receptor 4 (TLR-4) e metaloproteinase 9 da matriz (MMP-9)/inibidor de tecido da metaloproteinase 1 (TIMP-1) em vasos sanguíneos pulmonares com doença pulmonar obstrutiva crônica (DPOC) e suas relações com o remodelamento vascular pulmonar (PVR).

MÉTODOS: Sessenta tecidos paratumorais foram divididos em grupo COPD e o grupo controle $(n=30)$. Foram comparadas as inflamações, área da parede da artéria pulmonar/área da artéria total (WA\%) e espessura da parede/diâmetro externo vascular (WT\%). As expressões de TLR-4, MMP-9/TIMP-1 e PCNA em células de músculo liso vascular pulmonar foram detectadas, e suas relações com PVR foram então analisadas.

RESULTADOS: As inflamações (1,6 $\pm 0,8)$, WA $\%(44,0 \pm 6,4)$ e WT\% $(27,3 \pm 3,3)$ no grupo COPD foram maiores que no grupo controle $(0,3 \pm 0,5 ; 26,1 \pm 2,8 ; 15,6 \pm 1,8)$. E as expressões de TLR-4 (31,4 $\pm 14,7)$ e MMP-9/TIMP-1 (2,2 $\pm 2,6)$ foram aumentadas em relação ao grupo controle $(4,7 \pm 4,5,1,9 \pm 1,2)$. Na análise de correlação, TLR-4 e MMP-9/TIMP-1 foram positivamente correlacionadas com as inflamações ( $r=0,18 ; P<0,01)$, WA\% ( $r=0,68 ; P<0,01)$ e WT\% ( $r=0,73 ; P<0,01)$, bem como correlacionadas positivamente com a expressão de PCNA ( $r=0,44 ; P<0,01)$. A elevação da TLR-4 foi correlacionada positivamente com as expressões de MMP-9 e TIMP-1.

CONCLUSÕES: A regulação positiva do TLR-4 nas células do músculo liso arterial pulmonar de pacientes com DPOC poderia promover as inflamações e a expressão de MMP-9, causando assim uma degradação anormal da matriz extracelular, por isso desempenhou um papel importante no processo de PVR.

PALAVRAS-CHAVE: Pneumopatias. Doença pulmonar obstrutiva crônica. Metaloproteinase 9 da matriz. Fator 88 de diferenciação mieloide. Inibidores teciduais de metaloproteinases. Remodelação.

\section{REFERENCES}

1. Zhong N, Wang C, Yao W, Chen P, Kang J, Huang S, et al. Prevalence of chronic obstructive pulmonary disease in China: a large, population-based survey. Am J Respir Crit Care Med. 2007;176(8):753-60.

2. Mogensen $\mathrm{TH}$. Pathogen recognition and inflammatory signaling in innate immune defenses. Clin Microbiol Rev. 2009;22(2):240-73.

3. Basu S, Fenton MJ. Toll-like receptors: function and roles in lung disease. Am J Physiol Lung Cell Mol Physiol. 2004;286(5):L887-92.

4. Metcalfe HJ, Lea S, Hughes D, Khalaf R, Abbott-Banner K, Singh D. Effects of cigarette smoke on Toll-like receptor (TLR) activation of chronic obstructive pulmonary disease (COPD) macrophages. Clin Exp Immunol. 2014;176(3):461-72.

5. Meng Y, Yu CH, Li T, Li W, Cai SX, Li X. Expression and significance of Tolllike receptor-4 in rats lung established by passive smoking or associated with intratracheal instillation of lipopolysaccharide. Zhonghua Yi Xue Za Zhi. 2013;93(28):2230-4.

6. ji YY, Liu JT, Liu N, Wang ZD, Liu CH. PPARalpha activator fenofibrate modulates angiotensin II-induced inflammatory responses in vascular smooth muscle cells via the TLR4-dependent signaling pathway. Biochem Pharmacol. 2009;78(9):1186-97.
7. Ren X, Ge M, Qin X, Xu P, Zhu P, Dang Y, et al. S100a8/NF-кB signal pathway is involved in the $800-n m$ diode laser-induced skin collagen remodeling. Lasers Med Sci. 2016;31(4):673-8.

8. Jackson L, Cady CT, Cambier IC. TLR4-mediated signaling induces MMP9-dependent cleavage of B cell surface CD23. I Immunol. 2009;183(4):2585-92.

9. Zhang Z, Amorosa LF, Coyle SM, Macor MA, Lubitz SE, Carson JL, et al. Proteolytic cleavage of AMPK $\alpha$ and intracellular MMP9 expression are both required for TLR4-mediated mTORC1 activation and HIF-1 $\alpha$ expression in leukocytes. J Immunol. 2015;195(5):2452-60.

10. Dong YQ, Lu CW, Zhang L, Yang J, Hameed W, Chen W. Toll-like receptor 4 signaling promotes invasion of hepatocellular carcinoma cells through MKK4/JNK pathway. Mol Immunol. 2015;68(2 Pt C):671-83.

11. Gargiulo S, Gamba P, Testa G, Rossin D, Biasi F, Poli G, et al. Relation between TLR4/NF- $\kappa B$ signaling pathway activation by 27-hydroxycholesterol and 4-hydroxynonenal, and atherosclerotic plaque instability. Aging Cell. 2015;14(4):569-81.

12. Perros F, Lambrecht BN, Hammad H. TLR4 signalling in pulmonary stromal cells is critical for inflammation and immunity in the airways. Respir Res. 2011;12:125. 
13. Papakonstantinou E, Karakiulakis G, Batzios S, Savic S, Roth M, Tamm M, et al. Acute exacerbations of COPD are associated with significant activation of matrix metalloproteinase 9 irrespectively of airway obstruction, emphysema and infection. Respir Res. 2015;16:78.

14. Zhang L, Shi Y, Yuan L, Li X, Wang Y, Wang L, et al. Simvastatin re-balance the dis-regulated MMP-9 and MMP-12 versus TIMP-1 in rat chronic obstructive pulmonary disease model. | Biomater Tissue Eng. 2015;5(11):909-13.

15. Chaudhuri R, McSharry C, Brady |, Grierson C, Messow CM, Spears M, et al. Low sputum MMP-9/TIMP ratio is associated with airway narrowing in smokers with asthma. Eur Respir J.2014;44(4):895-904.

16. GOLD Executive Committee. Global strategy for the diagnosis, management and prevention of chronic obstructive pulmonary disease (revised 2011) [EB/ OL]. [cited 2012 Nov 16] Available from: http://www.goldcopd.com.

17. Barberà JA, Peinado VI, Santos S. Pulmonary hypertension in chronic obstructive pulmonary disease. Eur Respir J. 2003;21(5):892-905.

18. Retamales I, Elliott WM, Meshi B, Coxson HO, Pare PD, Sciurba FC, et al. Amplification of inflammation in emphysema and its association with latent adenoviral infection. Am | Respir Crit Care Med. 2001;164(3):469-73.

19. Lu YC, Yeh WC, Ohashi PS. LPS/TLR4 signal transduction pathway. Cytokine. 2008:42(2):145-51.

20. Lundberg AM, Hansson GK. Innate immune signals in atherosclerosis. Clin Immunol. 2010;134(1):5-24.
21. Wang $S$, Xiong L, Deng $X$, Ren W Zhu C, Li C, et al. Effects of simvastatin on airway inflammation and airway mucus hypersecretion in rats with chronic obstructive pulmonary disease. Zhonghua Yi Xue Za Zhi. 2015;95(22):1726-30.

22. Grenier D, Grignon L. Response of human macrophage-like cells to stimulation by Fusobacterium nucleatum ssp. nucleatum lipopolysaccharide. Oral Microbiol Immunol. 2006;21(3):190-6.

23. Kleiner DE, Stetler-Stevenson WG. Matrix metalloproteinases and metastasis. Cancer Chemother Pharmacol. 1999;43(Suppl):S42-51.

24. Ehrentraut $H$, Meyer R, Schwederski M, Ehrentraut S, Velten M, Grohé $\mathrm{C}$, et al. Systemically administered ligands of Toll-like receptor $2,-4$, and -9 induce distinct inflammatory responses in the murine lung. Mediators Inflamm. 2011;2011:746532.

25. Esa SA, Rawy AM, El-Behissy MM, Kamel MH, El-Hwaitty HM. Study of the level of sputum matrix metalloproteinase-9 (MMP-9) and tissue inhibitor metalloproteinase-1 (TIMP-1) in COPD patients. Egyptian | Chest Dis Tuber 2014:63(4):861-7.

26. Mercer PF, Shute IK, Bhowmik A, Donaldson GC, Wedzicha IA, Warner IA MMP-9, TIMP-1 and inflammatory cells in sputum from COPD patients during exacerbation. Respir Res. 2005;6:151.

27. Wang XM, Shi K, Li JJ, Chen TT, Guo YH, Liu YL, et al. Effects of angiotensin Il intervention on MMP-2, MMP-9, TIMP-1, and collagen expression in rats with pulmonary hypertension. Genet Mol Res. 2015;14(1):1707-17. 